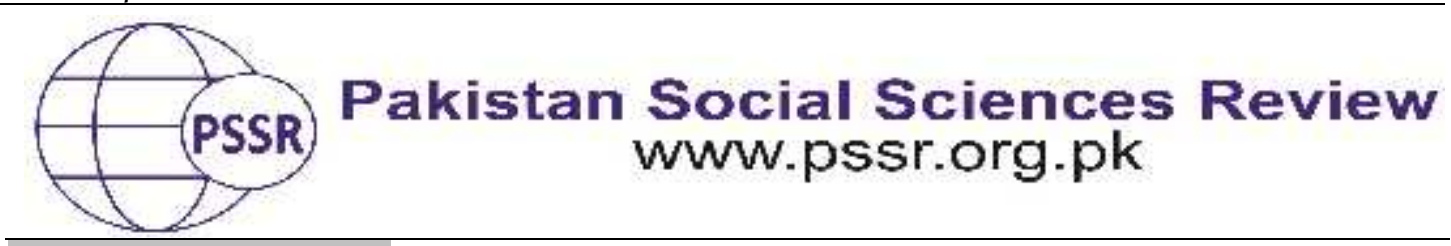

RESEARCH PAPER

\title{
Social Media Dependency and Socio-Cultural Integration: Case of Internally Displaced Persons in Pakistan
}

\author{
Muhammad Imran Khan ${ }^{1}$ Prof. Dr. Noshina Saleem ${ }^{2}$
}

1. Ph. D Scholar, Institute of Communication Studies, University of the Punjab, Lahore, Pakistan

2. Director Institute of Communication Studies, University of the Punjab, Lahore, Pakistan

\begin{tabular}{|c|c|}
\hline PAPER INFO & ABSTRACT \\
\hline $\begin{array}{l}\text { Received: } \\
\text { May 22, } 2020 \\
\text { Accepted: } \\
\text { August 25, } 2020 \\
\text { Online: } \\
\text { September } 15,2020\end{array}$ & $\begin{array}{l}\text { This empirical study explores the relationship between } \\
\text { dependency on social media and socio-cultural integration of } \\
\text { internally displaced persons (IDPs) belonging to the tribal } \\
\text { region of Pakistan. The study used a quantitative research } \\
\text { method for collecting the data from a sample of } 722 \text { IDPs. The }\end{array}$ \\
\hline $\begin{array}{l}\text { Keywords: } \\
\text { Migration, } \\
\text { Social Media } \\
\text { Dependency, } \\
\text { Socio-Cultural } \\
\text { Integration, } \\
\text { Tribal IDPs }\end{array}$ & $\begin{array}{l}\text { data was analyzed through hierarchical regression } \\
\text { techniques. The findings of this study revealed that the } \\
\text { dependency of IDPs on social media increases their inward } \\
\text { and outward socio-cultural integration. Resultantly, } \\
\text { dependency on social media leads IDPs towards hybrid } \\
\text { identity, where their socio-cultural links with the home }\end{array}$ \\
\hline Corresponding & $\begin{array}{l}\text { society as well as with the host community become stronger. } \\
\text { People and organizations working for IDPs can use social } \\
\text { media to solve their problems and help them in integration }\end{array}$ \\
\hline
\end{tabular}

\section{Introduction}

The widespread migration, both external and internal, is causing sociocultural and economic changes in contemporary societies, which was analyzed previously from cultural as well as structural perspectives (Portes, 2010). Scholars and policymakers are trying to devise ways to integrate these newcomers with diverse socio-cultural backgrounds into one unit. In this regard, previous studies suggested that mass media, particularly the new social media have an important role to play in the integration of minorities(Mittelstädt \& Odag, 2016; Sawyer \& Chen, 2012). But the role of social media use in the integration of ethnic minorities is still an under-researched field(Mittelstädt \& Odag, 2016).Therefore, this study focused on the role of social media in socio-cultural integration of internal migrants (internally displaced persons) of Tribal areas in Pakistan. This study aimed at bridging this gap, particularly regarding internal migrants (internally displaced 
persons or IDPs), because the majority of the previous studies on the relationship between mass media, particularly social media and socio-cultural integration of migrants were focused on external migrants (cross-border migrants).

The majority of IDPs in Pakistan are from the erstwhile Federally Administered Tribal Areas (FATA) located in the northwestern region of Pakistan along the Durand Line; the border between Pakistan and Afghanistan(Yousaf, Rasheed, \& Gul, 2018).FATA is Divided into seven tribal agencies (Bajaur, Mohmand, Khyber, Kurram, Orakzai, North Waziristan and South Waziristan), currently known as tribal districts and six frontier regions(Ali, 2018; Ullah, 2013). They migrated to other areas of Pakistan due to the successive military operations of Pakistan Army against the Taliban militants in the FATA region after 9/11. According to the estimates, Pakistan has hosted one of the highest numbers of IDPs in the world. At the end of 2014, there were nearly 4.1 million IDPs in South Asia, 46 percent of which were in Pakistan, majority of whom were displaced due to the military operations in the FATA region of Pakistan (Bilak et al., 2015).

According to the UNHCR 2015 mid-year report, 1.6 million IDPs in Pakistan were protected or assisted by UNHCR, which includes 309,200 newly displaced during the first half of 2015. Recent reports suggest that majority of the IDPs from tribal areas of Pakistan have been sent back, but still IDPs from some tribal areas are waiting for repatriation. But on the other hand, media reports suggest that those who were repatriated, are coming back due to lack of facilities, damages to houses and other properties and lack of security at some places.

FATA was previously governed through special laws known as Frontier Crimes Regulations (FCR), which are different from the laws of the mainland of Pakistan. These laws gave FATA a special status of semi-autonomy where the government had little control over the social and civic life of the people of the area. Though the tribal culture and society have undergone strong changes due to the displacement, still the culture and tradition play a vital role in matters of everyday life.

\section{Literature Review}

Socio-cultural integration is a process through which minority social groups are either assimilated into majority groups or results in interactive integration (social intercourse, friendship, marriage and membership of social organizations) or identificational integration (ethnic, regional, local and national feelings of belongingness) (King \& Skeldon, 2010). But the newcomers in a society do not adopt the same pattern of adjustment, rather they tend to fluctuate among different patterns of socio-cultural integration (Elias, 2003).

Some researchers argued that social media not only strengthen the relationship among the members of the diaspora of migrants, but also support their relationship with the people of other ethnic groups (Cornelius, Komito, \& Bates, 
2009; Dekker, Belabas, \& Scholten, 2015; Muzaffar, et. al. 2019) which helps multiethnic societies to find points of convergence for the migrants to reduce the differences among the host community and the newcomers (Wachanga, 2015). Social media is considered a suitable source for newcomers to find a place for their settlement in the host society (Charmarkeh, 2013)

Previous studies on media and socio-cultural integration show that immigrants use the internet both for adapting to their new environment by getting online information about various aspects of the host society and for getting information about their home country are either absent or biased on mainstream media (Elias, 2013). A previous study by Elias and Lemish (2011) shows that young Russian migrants in Israel expressed a higher level of trust on Israeli websites for news about politics, host community culture and information useful for everyday life and public behavior in the new society. Similarly, social media connects the international students with friends, family members back at home country and other compatriots in their host country on one hand, and on the other hand it also help them to find and connect with new friends in their host country (Hepp, Bozdag, \& Suna, 2012; Zhu \& Krever, 2016).

Social media helps the immigrants in adaption to the host society as well as strengthening their ties with the home country by communicating with family and friends at home as well as with friends in the host community, (Sawyer \& Chen, 2012).Internet is an integral part of South Asian immigrants living in the UK, and they use it to engage in discussion with online 'ethnic peer groups' without meeting them face to face (Thompson, 2002). They use these online platforms for information, keep connected with their families back at home and share their ideas and experiences with other people (Abegaz, 2013; Thompson, 2002).

\section{Hypotheses}

H1: IDP's dependency on social media for home society related issues has a positive significant relationship with their inward socio-cultural integration

H2: IDP's dependency on social media for home society related issues has a negative significant relationship with their outward socio-cultural integration

H3: IDP's dependency on social media for host society related issues has a negative significant relationship with their inward socio-cultural integration

H4: IDP's dependency on social media for host society related issues has a positive significant relationship with their outward socio-cultural integration 


\section{Material and Methods}

This study is based on the framework provided by Media System Dependency (MSD) theory presented by Ball-Rokeach and DeFleur (1976). Previous studies (Elias, 2003) also used MSD theory to study the media role in social and cultural integration. MSD theory holds that in societies with a higher concentration of media and drastic social changes, people will depend on media for information and understanding (Ball-Rokeach, 1985; Ball-Rokeach \& DeFleur, 1976). This media dependency, while competing with other sources of information, such as interpersonal communication, can affect the goal-oriented individuals (BallRokeach, 1998; Jackob, 2010; Melton \& Johnson, 2007)

This study focused on measuring the individual or micro level media dependencies of tribal IDP's and how their media dependency play role in their socio-cultural integration in the host society as well as with their original home community. For this purpose, the researchers used a quantitative survey method with cross-sectional research design. A closed-ended questionnaire was distributed for collecting the data from $1^{\text {st }}$ September to $25^{\text {th }}$ November 2018.

\section{Population}

The tribal IDPs who left their homes and are living in different settle areas of Pakistan due to military operations in tribal areas comprised the population for this study. Initially,336,042 families from FATA were displaced, out of which 279,692 families were officially returned, but still, 56,350 families from five agencies (NWA, SWA, Khyber, Orakzai and Kurram agencies) are displaced (FDMA, 2016). Media reports suggest that many IDP's are returning from tribal areas to their areas of settlement due to lack of facilities in their home towns.

\section{Sampling}

Due to the non-availability of detailed data on individual IDP's, the researchers could not use a random method for sample selection. Therefore, this study adopted the purposive method of sampling. Only those individuals were included in the sample, which migrated due to military operations and not due to other reasons (Job, education, business etc.).

Government has established camps and registration centers at different locations for the tribal IDPs. The sample was selected from these IDP camps and registration centers. The researchers visited these places and distributed a questionnaire among the IDPs present at those centers. Initially, 800 questionnaires were distributed among the IDPs. Out of which 756 questionnaires were returned. After screening and cleaning process, 722 questionnaires remained which form the final sample size for the study. Gay (2003) suggested that in quantitative studies, for a population higher than 5,000, a sample size of 400 is sufficient. 


\section{Measurement Tool}

The data was collected through a questionnaire adapted from (Adoni, Caspi, \& Cohen, 2006) with certain changes. The questionnaire included questions to measure the constructs of the study. The constructs of the study include demographic variables, dependency on social media and interpersonal communication (control variable) and socio-cultural integration. Demographic variables include gender, age, and education, and displacement period, city of settlement, current residence status and employment status.

The MSD theory defines dependency as the intensity of relationships, and for individuals, MSD operationally defined intensity as "perceived helpfulness of media" in satisfaction of goals (Ball-Rokeach, 1998). Therefore, in this study dependency was measured by knowing "helpfulness of social media" for information, orientation and play related goals. Five statements were provided about the helpfulness of interpersonal communication and seven statements about the helpfulness of media for home-related issues and six statements for social media's helpfulness for host society related issues were provided. Mean scores of social media dependency for home-related issues and host-related issues were computed separately.

\section{Socio-Cultural Integration}

This study adapted, the indicators from the previous studies of (Elias, 2003; Fokkema \& Haas, 2015) to measure socio-cultural integration. They used measurement scale with the two ends representing the inward and outward integration in such a way that one is in opposition to the other and the midpoint represents hybrid identity. Those studies were about the integration of migrants who were from completely different countries while this study is about IDPs who are the citizens of Pakistan but have certain internal differences. Instead, this study measured inward and outward integration separately, but on the same indicators. As a result, the study had two separate measures of integration; one for home society and culture (inward integration) and another for host society and culture (outward integration).

\section{Validity and reliability}

The questionnaire was analyzed by ten (10) faculty members of Media Studies departments in Gomal University Dera Ismail Khan, Khushal Khan University Karak and Kohat University of Science and Technology. The faculty members were asked to analyze the face validity of the questionnaire.

Internal consistency of constructs was measured using Cronbach's Alpha. As a general rule of thumb, studies mostly consider Cronbach's Alpha higher than 0.7 as acceptable. All the results of Cronbach's Alpha are above acceptable range 
Table 1

Reliability of various constructs

\begin{tabular}{clcc}
\hline No & \multicolumn{1}{c}{ Constructs } & No. of items & $\begin{array}{c}\text { Cronbach's } \\
\text { Alpha }\end{array}$ \\
\hline 11 & $\begin{array}{l}\text { Dependency on social media for home } \\
\text { society related issues }\end{array}$ & 7 & .94 \\
\hline 12 & $\begin{array}{l}\text { Dependency on social media for host society } \\
\text { related issues }\end{array}$ & 7 & .81 \\
\hline 13 & $\begin{array}{l}\text { Dependency on interpersonal } \\
\text { communication }\end{array}$ & 5 & .83 \\
\hline 14 & Inward socio-cultural integration & 9 & .88 \\
\hline 15 & Outward socio-cultural integration & 9 & .88 \\
\hline Note: & Results are rounded off to two decimal points, $\mathrm{n}=300$. &
\end{tabular}

\section{Results and Discussions}

Using Hierarchical Multiple Regression, preliminary analysis showed higher multicollinearity between the two major independent variables, i.e. dependency on social media for home society and dependency on social media for host society related issues. Therefore, the researchers used the test separately for both independent variables.

Assumptions of the test were checked before using the test. All the assumption (multicollinearity, autocorrelation and normal distribution of the dependent variable) were between the normal ranges. For all the tests, demographic variables were entered in the first step, dependency on interpersonal communication in the second step and dependency on social media in the third step. This allowed the researchers to control for demographic variables and dependency on interpersonal communication.

In all the four tests, $\mathrm{R}^{2}=.09$ for the first step shows that background variables were able to significantly predict $9 \%$ variance in inward as well as in outward integration of tribal IDPs. For inward socio-cultural integration $\Delta \mathrm{R}^{2}=.05$ for the second step suggested that interpersonal communication can significantly predict $5 \%$ inward integration of IDP who are dependent on social media either for home society related issues or for host society related issues.

For outward socio-cultural integration $\Delta \mathrm{R}^{2}=.24$ for the second step suggested that interpersonal communication can significantly predict $24 \%$ outward integration of IDP who are dependent on social media either for home society related issues or for host society related issues. The rest of the data is explained at the end of each table. 
Table 2

Hierarchical Multiple Regression Analyses Predicting Inward Socio-cultural Integration from Dependence on Social Media for Home Society Related Issues, after controlling for background Variables and Interpersonal Communication

\begin{tabular}{|c|c|c|c|c|c|c|c|c|}
\hline & \multicolumn{2}{|c|}{ Model 1} & \multicolumn{3}{|c|}{ Model 2} & \multicolumn{3}{|c|}{ Model 3} \\
\hline & B & SE $\beta$ & B & SE & B & B & SE & $\beta$ \\
\hline Gender & $-.17 \quad .06$ & $-.11^{* *}$ & -.21 & .06 & $-.14^{* * *}$ & -.06 & .06 & -.04 \\
\hline Age & $.06 \quad .03$ & .07 & .08 & .03 & $.09^{*}$ & .05 & .03 & .06 \\
\hline Education & .03 & $.16^{* * *}$ & .10 & .03 & $.12^{* *}$ & .10 & .03 & $.12^{* * *}$ \\
\hline Displacement period & .01 & .01 & .02 & .02 & .04 & .06 & .02 & $.14^{* *}$ \\
\hline City of settlement & .01 & .02 & .02 & .03 & .03 & .02 & .03 & .04 \\
\hline Residential Status & $-.09 \quad .04$ & $-.07^{*}$ & -.06 & .04 & -.05 & -.07 & .04 & -.06 \\
\hline Employment status & $-.16 \quad .03$ & $-.19^{* * *}$ & -.17 & .03 & $-.20^{* * *}$ & -.20 & .03 & $-.24^{* * *}$ \\
\hline $\begin{array}{l}\text { Interpersonal } \\
\text { Communication }\end{array}$ & & & .18 & .03 & $.22^{* * *}$ & .03 & .03 & .04 \\
\hline \multicolumn{6}{|c|}{$\begin{array}{l}\text { Dependence on Social Media for Home } \\
\text { society related issues }\end{array}$} & .21 & .03 & $.33^{* * *}$ \\
\hline \multicolumn{2}{|c|}{$\mathrm{R}^{2}$} & .09 & \multicolumn{3}{|c|}{.14} & \multicolumn{3}{|c|}{.21} \\
\hline $\mathrm{R}^{2}$ Adjusted & \multicolumn{2}{|r|}{.08} & \multicolumn{3}{|c|}{.13} & \multicolumn{3}{|c|}{.20} \\
\hline$\Delta \mathrm{R}^{2}$ & \multicolumn{2}{|r|}{.09} & \multicolumn{3}{|c|}{.05} & \multicolumn{3}{|c|}{.08} \\
\hline $\mathrm{F}$ & \multicolumn{2}{|c|}{$9.88^{* * *}$} & \multicolumn{3}{|c|}{$13.87^{* * *}$} & \multicolumn{3}{|c|}{$21.06^{* * *}$} \\
\hline
\end{tabular}

Durbin-Watson $=1.51$

$\mathrm{n}=722$; Dependent Variable: Inward Integration; $\Delta \mathrm{R}^{2}=\mathrm{R}^{2}$ Changed;* $\mathrm{p}<.05 ;{ }^{* *} \mathrm{p}<.01$; $* * * \mathrm{p}<.001$.

The table shows the results of hierarchical multiple regressions for inward integration of IDPs with predictor variables of Dependency on social media for home society related issues. The $\Delta \mathrm{R}^{2}=.08$ for the third step shows that dependency on social media for home society related issues can significantly predict $08 \%$ variance in inward integration of IDPs after controlling for background variables and interpersonal communication. Standardized beta values show dependency social media for home society related issues has a significant positive relationship with inward integration of IDPs.

These results rejected null hypothesis for dependency on social media for home society related issues. The research hypothesis of this study (H1) is supported. The dependency of IDPs on social media for issues related to their home society can increase their inward integration. Previous studies also suggested that migrants use social media to communicate with people from their home society (Thompson, 2002) and connect with their family and friends (Abegaz, 2013; Thompson, 2002) 
Table 3

Hierarchical Multiple Regression Analyses Predicting Outward Socio-cultural Integration from Dependence on Social Media for Home Society Related Issues after controlling for background Variables and Interpersonal Communication

\begin{tabular}{|c|c|c|c|c|c|c|}
\hline & \multicolumn{2}{|r|}{ Model 1} & \multicolumn{2}{|r|}{ Model 2} & \multicolumn{2}{|r|}{ Model 3} \\
\hline & B & SE & B & SE & B & SE \\
\hline Gender & -.13 & -.07 & -.25 & $.06-.14^{* * *}$ & -.02 & -.01 \\
\hline Age & .13 & $.13^{* *}$ & .19 & $.03 \quad .19^{* * *}$ & .14 & $.14^{* * *}$ \\
\hline Education & .02 & .02 & -.05 & -.05 & -.06 & $-.06^{*}$ \\
\hline Displacement Period & -.05 & $-.11^{*}$ & -.02 & -.04 & .04 & $.10^{*}$ \\
\hline City of settlement & .08 & $.12^{*}$ & .10 & $.03 .14^{* *}$ & .11 & $.02 .15^{\text {**x}}$ \\
\hline Residential Status & -.22 & $.05-.16^{* * *}$ & -.14 & $.04-.11^{* *}$ & -.17 & $.04 \stackrel{-}{.12^{* * *}}$ \\
\hline Employment status & .09 & $.10^{* *}$ & .08 & $.03 \quad .08^{*}$ & .03 & $.03 \quad .03$ \\
\hline Interpersonal Communication & & & .48 & $.03 .51^{* * *}$ & .24 & $.26^{* * *}$ \\
\hline $\begin{array}{l}\text { Dependence on Social Media for } \\
\text { Home society related issues }\end{array}$ & & & & & .34 & $.02 .48^{* * *}$ \\
\hline $\mathrm{R}^{2}$ & & .09 & & .33 & & .47 \\
\hline $\mathrm{R}^{2}$ Adjusted & & .08 & & .32 & & .46 \\
\hline$\Delta \mathrm{R}^{2}$ & & .09 & & .24 & & .14 \\
\hline $\mathrm{F}$ & & $10.56^{* * *}$ & & $44.55^{* * *}$ & & $69.83^{* * *}$ \\
\hline Durbin-Watson= 1.61 & & & & & & \\
\hline
\end{tabular}

The table shows the results of hierarchical multiple regressions for outward integration of IDPs with the predictor variable of Dependency on social media for home society related issues. The $\Delta \mathrm{R}^{2}=.14$ for the third step shows that dependency on social media for home society related issues can significantly predict $14 \%$ variance in outward integration of IDPs after controlling for background variables and interpersonal communication. Standardized beta values show dependency on social media for home society related issues has a significant positive relationship with outward integration of IDPs.

These results rejected null hypothesis for dependency on social media for home society related issues. The research hypothesis of this study (H2) is not supported, because the relationship is positive. The dependency of IDPs on social media for issues related to the home society can increase their integration with the society in which they are settled after their displacement. Other studies also indicated that irrespective of the purpose of social media use, it helps newcomers to integrated socially and culturally in the host society (Elias, 2013; Elias \& Lemish, 2009). 
Table 4

Hierarchical Multiple Regression Analyses Predicting Inward Socio-cultural Integration from Dependence on Social Media for Host Society Related Issues after controlling for background Variables and Interpersonal Communication

\begin{tabular}{|c|c|c|c|c|c|c|c|c|c|}
\hline & \multicolumn{3}{|c|}{ Model 1} & \multicolumn{3}{|c|}{ Model 2} & \multicolumn{3}{|c|}{ Model 3} \\
\hline & B & SE & $\beta$ & B & SE & B & B & SE & $\beta$ \\
\hline Gender & -.17 & .06 & $-.11^{* *}$ & -.21 & .06 & $-.14^{* * *}$ & -.02 & .06 & -.01 \\
\hline Age & .06 & .03 & .07 & .08 & .03 & $.09^{*}$ & .07 & .03 & $.08^{*}$ \\
\hline Education & .12 & .03 & $.16^{* * *}$ & .10 & .03 & $.12^{* *}$ & .06 & .03 & $.08^{*}$ \\
\hline Displacement period & .01 & .02 & .01 & .02 & .02 & .04 & .08 & .02 & $.19^{* * *}$ \\
\hline City of settlement & .01 & .03 & .02 & .02 & .03 & .03 & .04 & .03 & .06 \\
\hline Residential Status & -.09 & .04 & $-.07^{*}$ & -.06 & .04 & -.05 & -.11 & .04 & $-.09^{*}$ \\
\hline Employment status & -.16 & .03 & $-.19^{* * *}$ & -.17 & .03 & $-.20^{* * *}$ & -.19 & .03 & $-.23^{* *}$ \\
\hline $\begin{array}{l}\text { Interpersonal } \\
\text { Communication }\end{array}$ & & & & .18 & .03 & $.22 * * *$ & .10 & .03 & $.13^{* * *}$ \\
\hline \multicolumn{2}{|c|}{$\begin{array}{l}\text { Dependence on Social Media } \\
\text { for Host society related issues }\end{array}$} & & & & & & .24 & .03 & $.38^{* * *}$ \\
\hline \multicolumn{2}{|c|}{$\mathrm{R}^{2}$} & \multicolumn{2}{|r|}{.09} & \multicolumn{3}{|c|}{.14} & \multicolumn{3}{|c|}{.23} \\
\hline \multicolumn{2}{|l|}{$\mathrm{R}^{2}$ Adjusted } & \multicolumn{2}{|r|}{.08} & \multicolumn{3}{|c|}{.13} & \multicolumn{3}{|c|}{.22} \\
\hline \multicolumn{2}{|l|}{$\Delta \mathrm{R}^{2}$} & \multicolumn{2}{|r|}{.09} & \multicolumn{3}{|c|}{.05} & \multicolumn{3}{|c|}{.09} \\
\hline \multicolumn{2}{|l|}{$\mathrm{F}$} & \multicolumn{2}{|c|}{$9.88^{* * *}$} & \multicolumn{3}{|c|}{$13.87^{* * *}$} & \multicolumn{3}{|c|}{$23.26^{* * *}$} \\
\hline
\end{tabular}

Durbin-Watson $=1.51$

$\mathrm{n}=722$; Dependent Variable: Inward Integration; $\Delta \mathrm{R}^{2}=\mathrm{R}^{2}$ Changed; ${ }^{*}<.05 ;{ }^{* *} \mathrm{p}<.01$; $* * * p<.001$.

The table shows the results of hierarchical multiple regression for inward integration of IDPs with predictor variables of Dependency on social media for host society related issues. The $\Delta \mathrm{R}^{2}=.09$ for the third step shows that dependency on social media for host society related issues can significantly predict $09 \%$ variance in inward integration of IDPs after controlling for background variables and interpersonal communication. Standardized beta values show the dependency of social media for host society related issues has a significant positive relationship with inward integration of IDPs.

These results rejected null hypothesis for dependency on social media for host society related issues. The research hypothesis of this study (H3) is not supported, because the relationship is positive. The dependency of IDPs on social media for issues related to the host society can increase their integration with their home society(Hepp et al., 2012; Zhu \& Krever, 2016). 
Table 5

Hierarchical Multiple Regression Analyses Predicting Outward Socio-cultural Integration from Dependence on Social Media for Host Society Related Issues after Controlling for background Variables and Interpersonal Communication

\begin{tabular}{|c|c|c|c|c|c|c|c|c|}
\hline & \multicolumn{3}{|c|}{ Model 1} & \multicolumn{2}{|r|}{ Model 2} & \multicolumn{3}{|c|}{ Model 3} \\
\hline & B & SE & $\beta$ & B & SE & B & SE & $\beta$ \\
\hline Gender & -.13 & .07 & -.07 & -.25 & $.06-.14^{* \star *}$ & -.02 & .06 & -.01 \\
\hline Age & .13 & .04 & $.13^{* *}$ & .19 & $.03 .19^{* * *}$ & .18 & .03 & $.18^{* * *}$ \\
\hline Education & .02 & .03 & .02 & -.05 & $.03 \quad-.05$ & -.10 & .03 & $-.10^{* *}$ \\
\hline Displacement period & -.05 & .02 & $-.11^{*}$ & -.02 & -.04 & .06 & .02 & $.12^{* *}$ \\
\hline City of settlement & .08 & .03 & $.12^{*}$ & .10 & $.03 .14^{* *}$ & .12 & .03 & $.17^{* * *}$ \\
\hline Residential Status & -.22 & .05 & $-.16^{* * *}$ & -.14 & $.04-.11^{* *}$ & -.20 & .04 & $-.15^{* *}$ \\
\hline Employment status & .09 & .04 & $.10^{* *}$ & .08 & $.03 \quad .08^{*}$ & .05 & .03 & .05 \\
\hline \multicolumn{2}{|c|}{ Interpersonal Communication } & & & .48 & $.03 .51^{* * *}$ & .39 & .03 & $.41^{* * *}$ \\
\hline \multicolumn{2}{|c|}{$\begin{array}{l}\text { Dependence on Social Media for } \\
\text { Host society related issues }\end{array}$} & & & & & .29 & .03 & $.39 * * *$ \\
\hline \multicolumn{2}{|l|}{$\mathrm{R}^{2}$} & \multicolumn{2}{|c|}{.09} & \multicolumn{2}{|r|}{.33} & \multicolumn{3}{|c|}{.43} \\
\hline \multicolumn{2}{|l|}{$\mathrm{R}^{2}$ Adjusted } & \multicolumn{2}{|c|}{.08} & \multicolumn{2}{|r|}{.33} & \multicolumn{3}{|c|}{.42} \\
\hline \multicolumn{2}{|l|}{$\Delta \mathrm{R}^{2}$} & \multicolumn{2}{|c|}{.09} & \multicolumn{2}{|r|}{.24} & \multicolumn{3}{|c|}{.10} \\
\hline \multicolumn{2}{|l|}{ F } & \multicolumn{2}{|c|}{$10.56^{* * *}$} & \multicolumn{2}{|r|}{$44.55^{* * *}$} & \multicolumn{3}{|c|}{$59.86^{* * *}$} \\
\hline
\end{tabular}

Durbin-Watson $=1.61$

$\mathrm{n}=722$; Dependent Variable: Outward Integration; $\Delta \mathrm{R}^{2}=\mathrm{R}^{2}$ Changed; $\mathrm{p}<.05$; ${ }^{* *} \mathrm{p}<.01 ;{ }^{* * *} \mathrm{p}<.001$

The table shows the results of hierarchical multiple regression for outward integration of IDPs with predictor variables of Dependency on social media for host society related issues. The $\Delta \mathrm{R}^{2}=.10$ for the third step shows that dependency on social media for host society related issues can significantly predict a $10 \%$ variance in outward integration of IDPs after controlling for background variables and interpersonal communication. Standardized beta values show dependency social media for host society related issues has a significant positive relationship with outward integration of IDPs.

These results rejected null hypothesis for dependency on social media for host society related issues. The research hypothesis of this study $(\mathrm{H} 4)$ is supported. The dependency of IDPs on social media for issues related to the society in which they are settled after displacement can increase their integration with their host society(Charmarkeh, 2013). Social media interactions help in reducing the differences among people of various groups (Wachanga, 2015).

\section{Conclusion}

The analysis of this study suggested that the relationships for all hypotheses were positively significant, which means that first and fourth hypotheses of the study are supported, while, unable to support the second and third hypotheses 
(which predicted negative relationships). This study concludes that dependency of IDPs on social media for issues related to either their home society or host society increase their inward as well as their outward socio-cultural integration. Resultantly, dependency on social media leads IDPs towards hybrid identity, where their socio-cultural links with the home society become stronger along with strengthening their relationship with the local community. The findings of this study also revealed that the purpose of social media use is not a significant contributor, and using it for home-related issues or host society related issues does not change its effects on socio-cultural integration of IDPs.

\section{Recommendations}

This study supports the broader use of social media for the integration of IDPs in the new settings as well as to create solidarity among the ethnic group. Therefore, policymakers should use the new media for helping IDPs to understand the culture of the host community which will help the newcomers in adjusting in their place of settlement. Similarly, social media can be used to inform the IDPs about development in their home society, which can encourage those people who want to go back. Researchers in future should focus on the ways IDPs are represented in different social media platforms as well as how different social media platforms like Facebook, Twitter, Youtube etc can play role in smoothening the process of IDP's socio-cultural integration. 


\section{References}

Abegaz, F. C. (2013). The media use of Ethiopians in Finland. (Master), University of Helsinki. Retrieved from https://helda.helsinki.fi/bitstream/handle/ 10138/ 38865/FevenThe\%20media\%20use\%20of\%20Ethiopian\%20in\%20Finland.pdf?se quence=1;

Adoni, H., Caspi, D., \& Cohen, A. A. (2006). Media, minorities, and hybrid identities: the Arab and Russian communities in Israel. Cresskill, New Jersey: Hampton Press.

Ali, I. (2018). Mainstreaming Pakistan's federally administered tribal areas. Special Report, 421.

Ball-Rokeach, S. J. (1985). The origins of individual media system dependency: A sociological framework. Communication Research, 12(4), 485-510.

Ball-Rokeach, S. J. (1998). A theory of media power and a theory of media use: Different stories, questions, and ways of thinking. Mass Communication and Society, 1(1-2), 5-40.

Ball-Rokeach, S. J., \& DeFleur, M. L. (1976). A dependency model of mass-media effects. Communication Research, 3(1), 3-21.

Bilak, A., Caterina, M., Charron, G., Crozet, S., Díaz-Leal, L. R., Foster, F., . . . Yonetani, M. (2015). Global Overview 2015: People internally displaced by conflict and violence. In J. Lennard (Ed.). Geneva: Internal Displacement Monitoring Centre, Norwegian Refugee Council.

Charmarkeh, H. (2013). Social media usage, tahriib (migration), and settlement among Somali refugees in France. Refuge: Canada's journal on refugees, 29(1), 4352.

Cornelius, I., Komito, L., \& Bates, J. (2009). Virtually local: social media and community among Polish nationals in Dublin. Paper presented at the Aslib Proceedings: New information perspectives, 61(3).

Dekker, R., Belabas, W., \& Scholten, P. (2015). Interethnic contact online: contextualising the implications of social media use by second-generation migrant youth. Journal of Intercultural Studies, 36(4), 450-467.

Elias, N. (2003). From the former Soviet Union to Israel and Germany: The roles of mass media in the social and cultural integration of immigrants. Paper presented at the EMTEL conference: "New Media and Everyday Life in Europe", London.

Elias, N. (2013). Immigrant children and media. The Routledge international handbook of children, adolescents and media, 336-343. 
Elias, N., \& Lemish, D. (2009). Spinning the web of identity: the roles of the internet in the lives of immigrant adolescents. New Media $\mathcal{E}$ Society, 11(4), 533-551.

Elias, N., \& Lemish, D. (2011). Between three worlds: Host, homeland, and global media in the lives of Russian immigrant families in Israel and Germany. Journal of Family Issues, 32(9), 1245-1274. DOI: 10.1177/0192513X11400837

Fokkema, T., \& Haas, H. (2015). Pre-and Post-Migration Determinants of Socio-Cultural Integration of African Immigrants in Italy and Spain. International Migration, 53(6), 3-26.

Hepp, A., Bozdag, C., \& Suna, L. (2012). Mediatized migrants: Media cultures and communicative networking in the diaspora. Migrations, diaspora, and information technology in global societies, 172-188.

Jackob, N. G. E. (2010). No alternatives? The relationship between perceived media dependency, use of alternative information sources, and general trust in mass media. International Journal of Communication, 4, 589-606

King, R., \& Skeldon, R. (2010). 'Mind the gap!'integrating approaches to internal and international migration. Journal of ethnic and migration studies, 36(10), 16191646.

Melton, J., \& Johnson, J. (2007). Measuring Internet dependency. Handbook of research on electronic surveys and measurements, 126-135.

Mittelstädt, A., \& Odag, Ö. (2016). Social Media Use and Social Integration of Ethnic Minorities in Germany: A New Interdisciplinary Framework Athens Journal of Mass Media and Communications, 2(1), 21-32.

Muzaffar, M. Chodhry, S. Afzal, N. (2019). Social Media and Political Awareness in Pakistan: A Case Study of Youth, Pakistan Social Sciences Review, Volume 3, Issue II, 1-13

Portes, A. (2010). Migration and social change: Some conceptual reflections. Journal of ethnic and migration studies, 36(10), 1537-1563.

Sawyer, R., \& Chen, G.-M. (2012). The impact of social media on intercultural adaptation. Intercultural Communication Studies, 21(2), 151-169.

Thompson, K. (2002). Border crossings and diasporic identities: Media use and leisure practices of an ethnic minority. Qualitative Sociology, 25(3), 409-418.

Ullah, A. (2013). Federally Administered Tribal Areas (FATA) of Pakistan: Study of a Special Model of Governance. Pakistan Journal of History and Culture, 34(2), 6594. 
Wachanga, D. N. (2015). Ethnic differences vs nationhood in times of national crises: The role of social media and communication strategies. Journal of African Media Studies, 7(3), 281-299.

Yousaf, F., Rasheed, H., \& Gul, I. (2018). FATA tribes: Finally out of colonial clutches. Past, present and future. Center for Research and Security Studies.

Zhu, R., \& Krever, R. (2016). Media use and cultural adaptation by foreign students in Chinese universities. Continuum, 1-18. 